\title{
Construction Design and Manufacturing of a Cylinder Liner of a Motorcycle
}

Adam Hamberger, Milan Daňa, Luboš Kroft

Regional Technological Institute, University of West Bohemia - Faculty of Mechanical Engineering, Univerzitní 8, Pilsen 306 14, Czech Republic. E-mail: adam26@students.zcu.cz

This work deals with the construction design and manufacturing of a cylinder liner which is used in a Jawa 50 motorcycle in order to increase the performance characteristics. The liner is pressed in the aluminium cylinder case with ribs so together it makes a two-stroke motorcycle cylinder. The first step was to build an analysis of the technical design of the original motorcycle cylinder to detect any restrictive parameters for the modifications, especially of the cylinder liner, so the motorcycle can be used for racing. As well as the construction design of the liner, the work deals with the clamping and manufacturing of this part too. The CNC code was written using SolidCAM software. Then the liner was manufactured in a turning-milling centre. The purpose of this work is to produce a liner so that it forms a racing motorcycle cylinder together with the aluminium case with the ribs. The basis of this project is the correctness of the construction design and the accuracy in manufacturing so that the engine can achieve the demanded parameters with respect to usability, engine cooling, gear setup, engine life and the other restrictive parameters.

Keywords: Cylinder liner, two-stroke cylinder, Jawa 50, increase performance, 5-axis milling

\section{Introduction}

Races for $50 \mathrm{cc}$ motorcycles have been popular since the middle of the last century. There are more categories in the Czech Republic, including Jawa 50 motorcycles. Machines with these liners are used in the road racing championships in the Czech Republic and the Šumava cup off-road races. For a motorcycle to win, it must have performance characteristics higher than the other machines on the starting list. The cylinder liner has a big potential to maximize the performance characteristics with other components of engine, and the performance can be increased about three times from the original values. Therefore it is necessary to pay attention to the liner for the good representation of the racing team, the engine designer and the results of the work from students in UWB Pilsen. The aim of this work is to analyse the details in cylinder liner with its design and manufacturing in order to increase the engine performance together with other modifications in the engine. The modifications were designed on the basis of a lot of experience with previous modifications which were carried out on the original liners with hand tools. The engineering design was created using Autodesk Inventor software and the production was done on a turning-milling centre. The finished liner is pressed in the aluminium cylinder case to form the race cylinder.

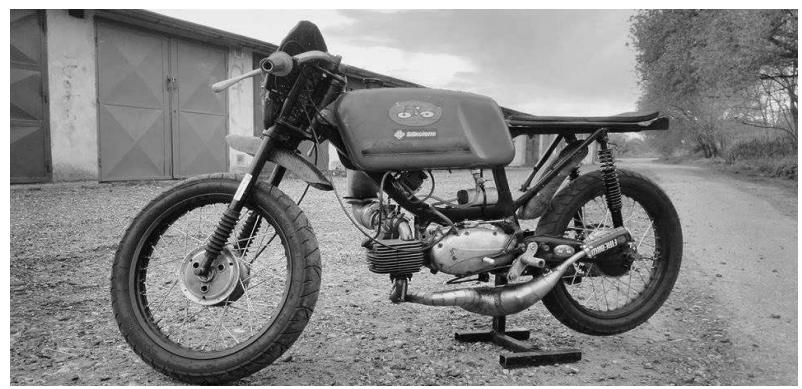

Fig. 1 Jawa 50 racing bike for Championship of Czech Republic in category $R S$.

\section{Organizing}

Two basic variants of the cylinders were designed. The first one is based on the original liner where all modifications are carried out with removal o material only because it is written in the rules of the Jawa RS category in the championship of the Czech Republic. This variant is marked as two-port (RS). Although it has in total four ports (as the original cylinder), it is usual to mark the cylinders according to the number of the transfer ports, not by the number of all the ports. The original layout means there is one exhaust port, one intake port and two transfer ports. This is one of the restrictions in the rules of the Jawa RS category.

The second variant is created from a cast iron tube with a totally new layout of all the ports. It was necessary to weld the ports in an aluminium case in order to create a new scavenging design. After that it is possible to create one double-exhaust port, one double-intake port and fiveport scavenging system. Because of this system the variant is marked as five-port (5K)

\section{Tab. 1 Basic information about variants}

\begin{tabular}{|l|l|l|}
\hline Variant & RS & $\mathbf{5 K}$ \\
\hline $\begin{array}{l}\text { Number of intake } \\
\text { ports / duration }\end{array}$ & $1 / 160^{\circ}$ & $2 / 160^{\circ}$ \\
\hline $\begin{array}{l}\text { Number of trans- } \\
\text { fer ports / dura- } \\
\text { tion }\end{array}$ & $2 / 125,5^{\circ}$ & $5 / 125,5^{\circ}$ \\
\hline $\begin{array}{l}\text { Number of ex- } \\
\text { haust ports / du- } \\
\text { ration }\end{array}$ & $1 / 172^{\circ}$ & $2 / 172^{\circ}$ \\
\hline $\begin{array}{l}\text { Workpiece/outer } \\
\text { diameter }\end{array}$ & $\begin{array}{l}\text { Original } \\
\text { liner } / 46 \mathrm{~mm}\end{array}$ & $\begin{array}{l}\text { Tube } / \\
50 \mathrm{~mm}\end{array}$ \\
\hline Purpose & $\begin{array}{l}\text { Road races } \\
\text { Jawa } 50 \mathrm{RS}\end{array}$ & Offroad races \\
\hline
\end{tabular}




\section{Engineering design}

The engineering design of both variants was created as a 3D model in Autodesk Inventor 2015. The turned diameters were dimensioned in consideration of possibilities of other components. This means the outer diameter for heat transfer to the aluminium case, the surface for the cylinder head, bore for the piston, etc. It is necessary to turn only the workpiece of the $5 \mathrm{~K}$ variant. The milled shapes for both variants were created using negatives of all the ports in order to optimize the mixture flow. The negatives were transferred in the complete cylinder. Then the model of the cylinder was divided into the liner and the aluminium case. The liner is made of cast-iron with lamellar graphite EN-GJL-250.

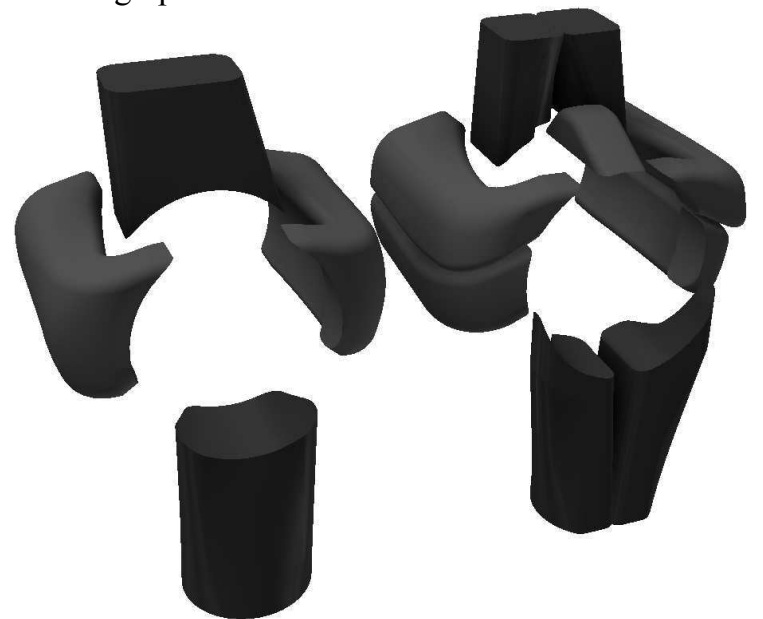

Fig. 2 Comparison of the port negatives of both variants

\section{Scavenging design}

A lot of experience was used with modifications carried out in the past with hand-tools and it was consulted with many experts. These experts are from factory development or they are interested in flow simulations, or they are persons who are known for their modifications of engines for motocross races.

Other dimensions in the engine must be taken in to account in order to squeeze the scavenging system into the cylinder. This is a big barrier to using a scavenging system from another modern racing motorcycle, because the transfer ports are in such positions that it is impossible to create the ports in a Jawa 50 cylinder. It was very important to put emphasis on the correct shapes of the crosssections of all the ports in many planes. The shapes are inspired by cylinders in racing machines from wellknown manufacturers. The duration of the porting was designed in such a way so as not to overrun an engine speed of 12000 RPM, because the primary transmission for driving the clutch is highly stressed by centrifugal forces. The clutch is driven by the chain from the crankshaft and the rules forbid changing this construction. This means that both variants have the same porting duration. It is necessary to create a process to determine the height of the ports from the values of porting duration in Tab. 1 . There are many options, but the most accurate is to make the piston movement equation depending on the crankshaft angle. The equation is based on the crankshaft scheme on Fig. 3. [1], [3], [4]

Function of the piston movement depending on crankshaft angle:

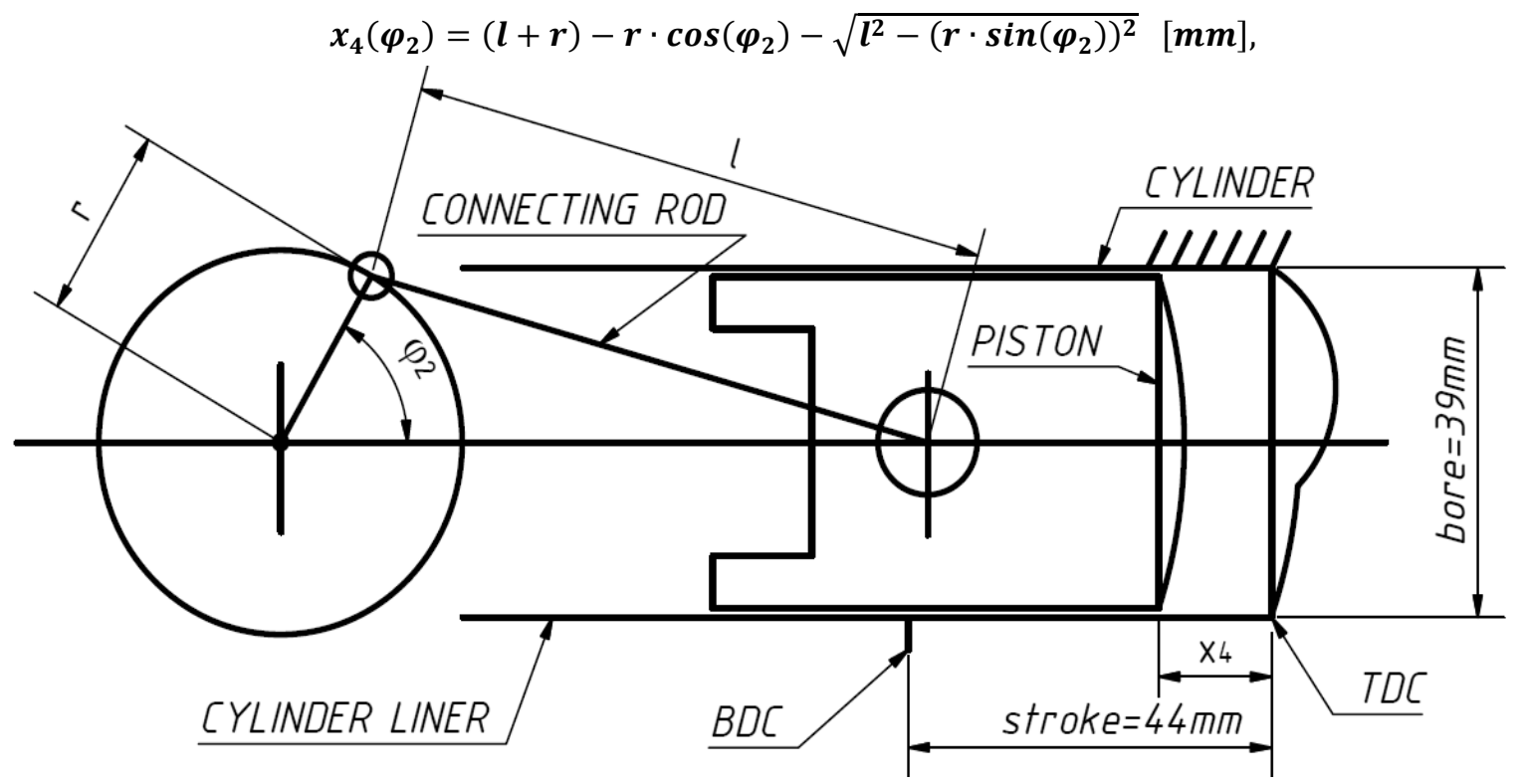

Fig. 3 Kinematic scheme of crankshaft

This function is valid only for a centric crankshaft, which means that the axis of the piston goes through the axis of the crankshaft. With this equation it is much easier to determine the manufactured dimensions, because it was absolutely normal to measure the dimensions directly with angle measurement in the past.

\section{Manufacturing}

Due to the sophisticated scavenging system, it is necessary to manufacture the complex shapes on the liner using 5-axis milling. Because this component needs turning and milling, it was very advantageous to use the 
CTX BETA 1250 TC 4A turning-milling centre at the Regional Technological Institute in Pilsen. CAM software SolidWorks was used to generate the toolpaths. It was necessary to design a strong clamping for turning and milling in one operation. The first requirement was the concentricity of the mean cylindrical part with the spindle. The second requirement was radial rigidity because of the milling in the tail section. The optimum solution is clamping in soft jaws in a universal chuck. There is a risk

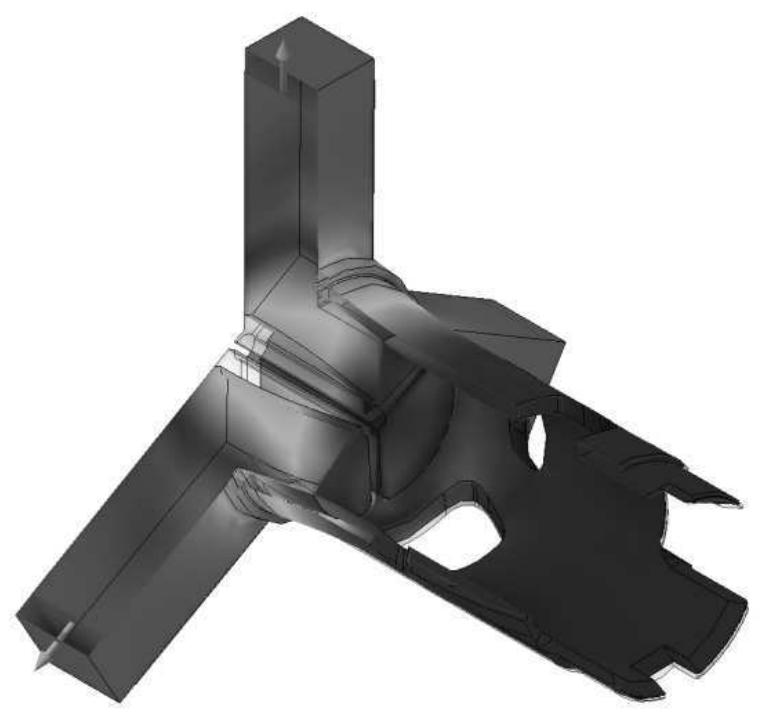

of destroying the liner when clamping, especially with variant RS, because it has a thinner wall. Stress distribution was determined using finite element method. To eliminate the possibility of destruction, it was necessary to decrease the pressure in the hydraulic system from 30 bars to 13 bar to operate the jaws. Whether the liner is deformed or not was checked on the experimental piece. [11]

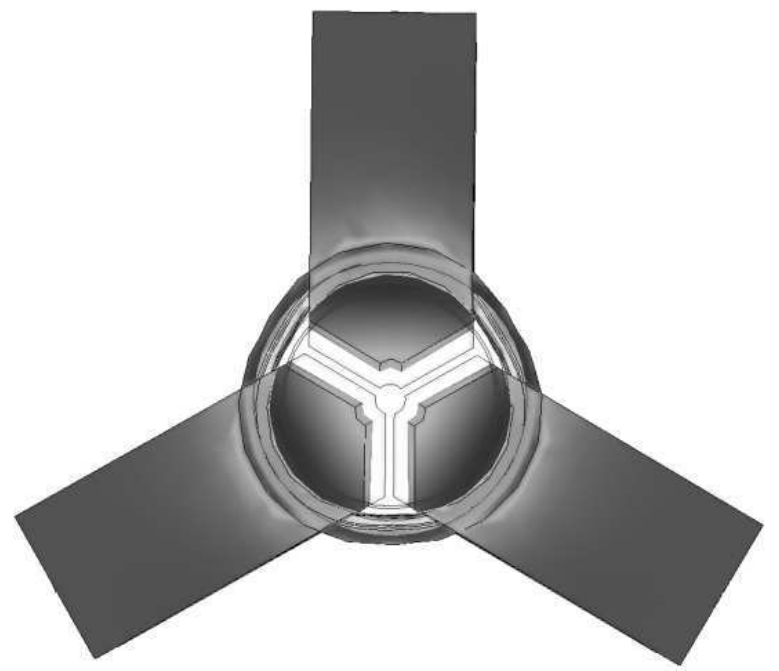

Fig. 4 Stress state according to Von Mises hypothesis

\section{Working procedure}

The working procedure for the $5 \mathrm{~K}$ liner is described here, because it is completely turned and milled. The RS liner is manufactured from the original liner, it is only milled and the procedure is not very different from the $5 \mathrm{~K}$ liner. The basic form is rotary and first it is necessary to turn it. When first clamping in the outer jaws, the area for the cylinder head and the bore are turned. The second clamping is in the inner jaws, and the rigidity of the whole system is increased by means of a live centre. When turning the outer diameter it is necessary to use the live centre, because there are high demands on roughness and geometrical quality. These requirements are very important because heat is transferred through this cylinder surface to the aluminium case. Interference between the liner and the case may be $0.05-0.07 \mathrm{~mm}$. Lower interference causes too low pressure on the cylinder contact surface, which means too low heat transfer and engine overheating.
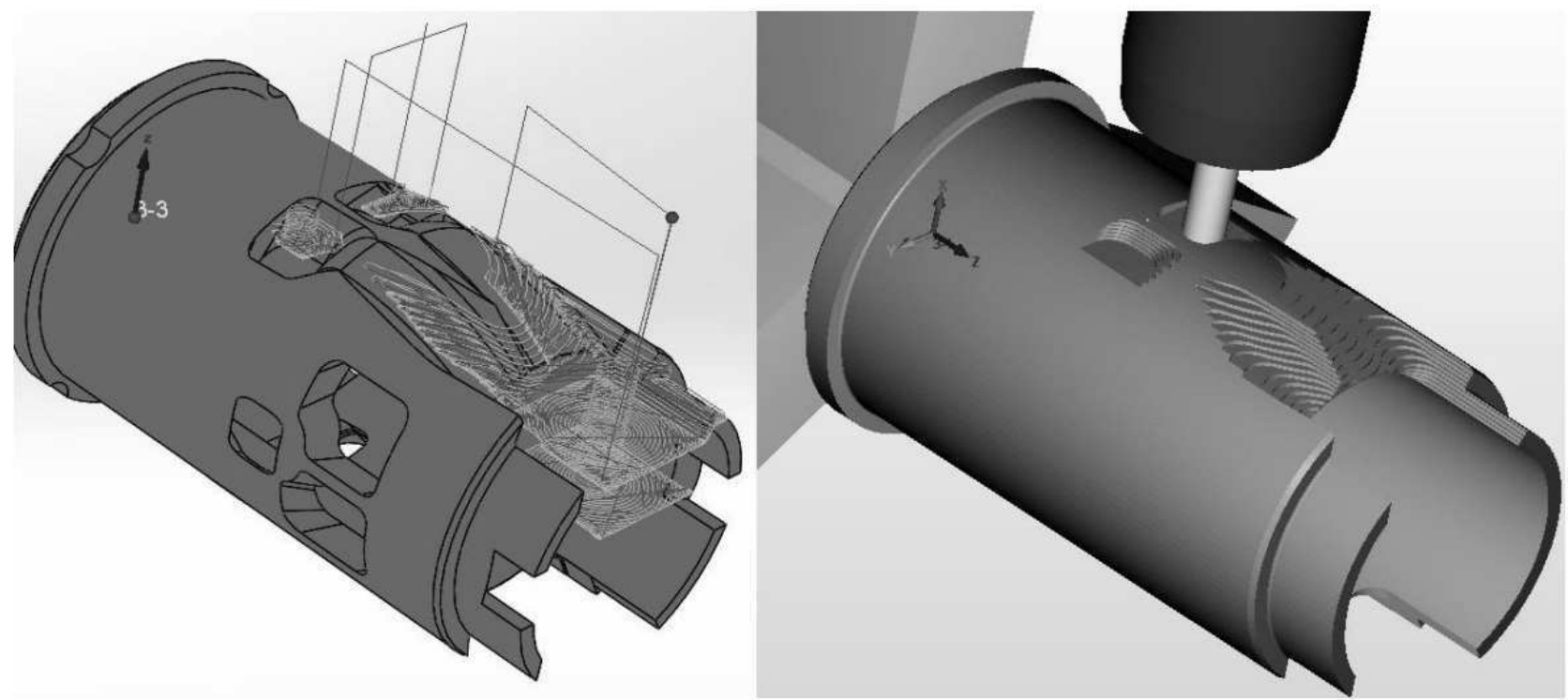

Fig. 5 Roughing by means of iMachining strategy 


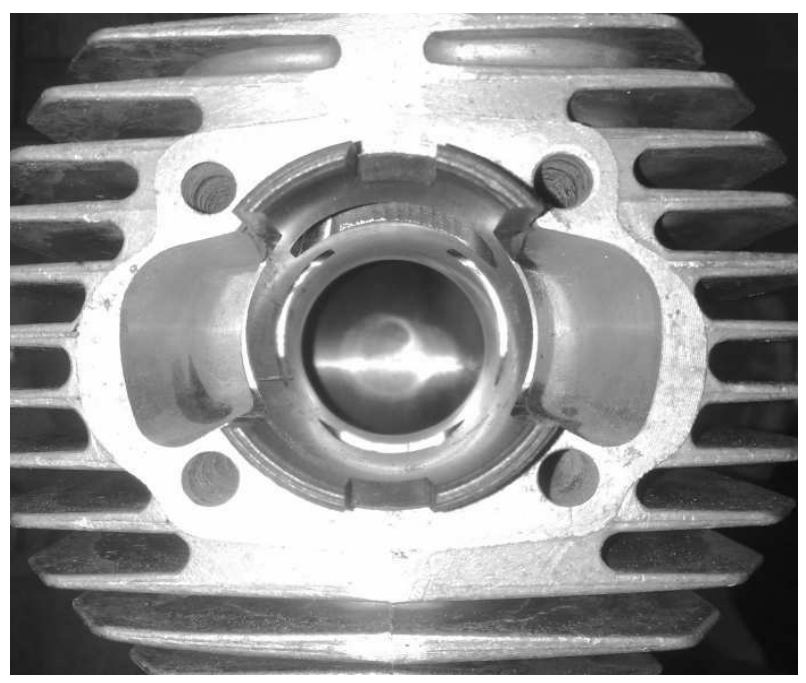

Fig. 6 Finished RS cylinder

Higher interference can cause problems when pressing the liner into the case. The last manufacturing part is the milling of the ports. Carbide monolithic tools were used with diameter 3 to $6 \mathrm{~mm}$ (the end mills and ball cutters). Shapes of the newly designed scavenging system are not flat, they are convex and concave. The transfer ports have the most difficult shapes. iMachining strategy was used for roughing and the finishing was done using flowline milling with tilt angle. It was necessary to use slim and long mill tools in order to manufacture deep ports with small radiuses. There was a big problem with the rigidity and vibration of the slim tools. It was important when creating the NC program to correctly setup the cutting conditions to prevent the tools breaking. In this case it was necessary to use 5-axis milling. Due to the fluent change of the tilt angle, it is possible to use shorter tools. Then it is possible to use a higher feed velocity and to manufacture all the ports as a whole in order to achieve a high quality of finished surface.

The finished liner is pressed in aluminium case, as shown on Fig. 6 . The pressed cylinder must be heated and cooled three-times slowly in order to minimize the deformation after honing. After this, the completed cylinder is ready to hone.

\section{Results}

Both variants were tested using a dynamometer to diagnose their performance characteristics. The first measurements proved that both variants without another racing component can improve the characteristics by almost two times. The next measurement with better and better components proved that it is possible to reach a speed of over $100 \mathrm{~km} / \mathrm{h}$.

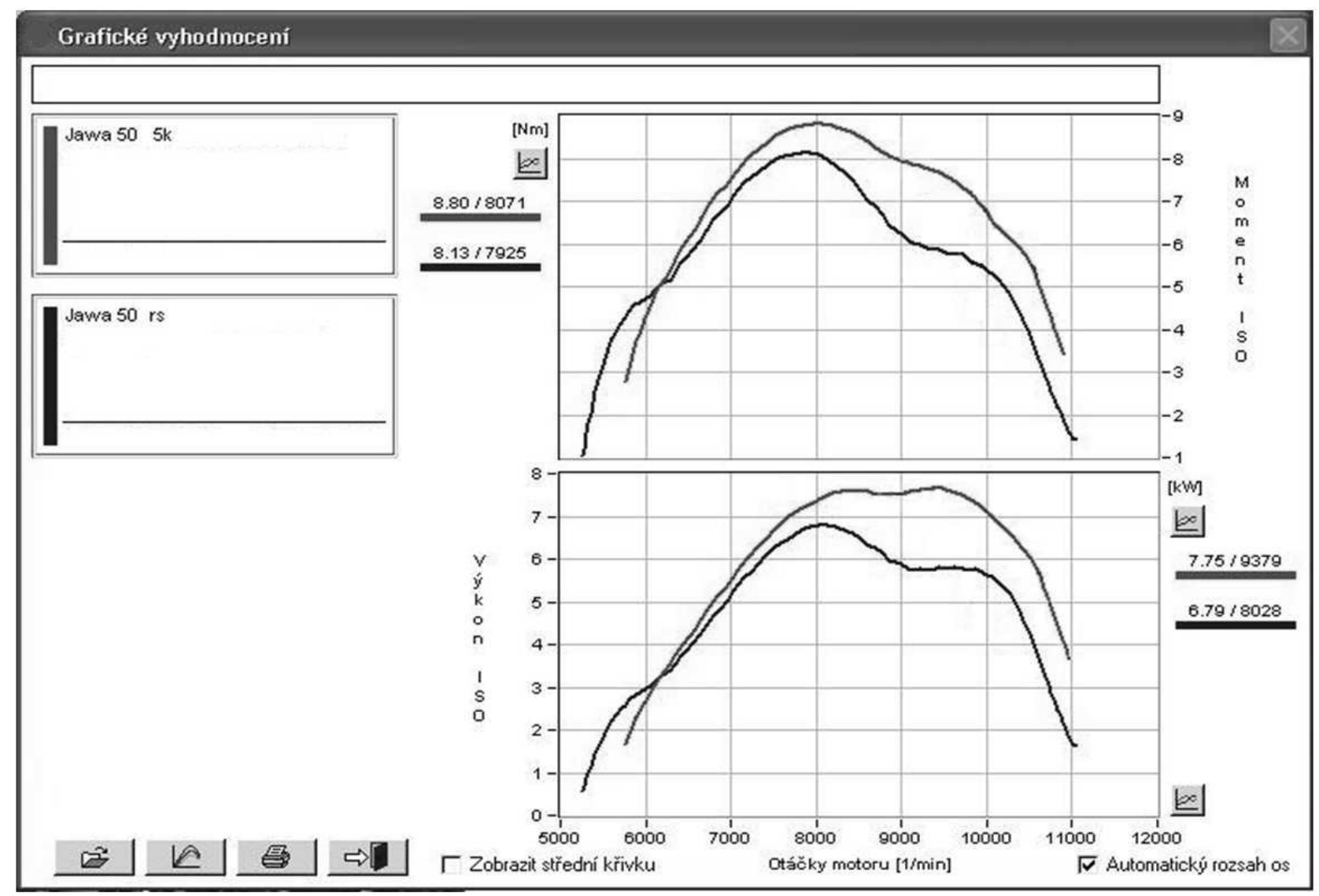

Fig. 7 Performance characteristics of both variants

By way of contrast, the original motorcycle reaches only $65 \mathrm{~km} / \mathrm{h}$. The graph of the last measurement is shown in Fig.7. As you can see, the $5 \mathrm{~K}$ variant has better performance characteristics, because its torque is higher at all revs. This result is not the end, because tuning and improving of performance will never end. Also the temporary results for the $5 \mathrm{~K}$ variant are $7.75 \mathrm{~kW}$ at 9379 RPM and for RS variant $6.79 \mathrm{~kW}$ at $8028 \mathrm{RPM}$. 


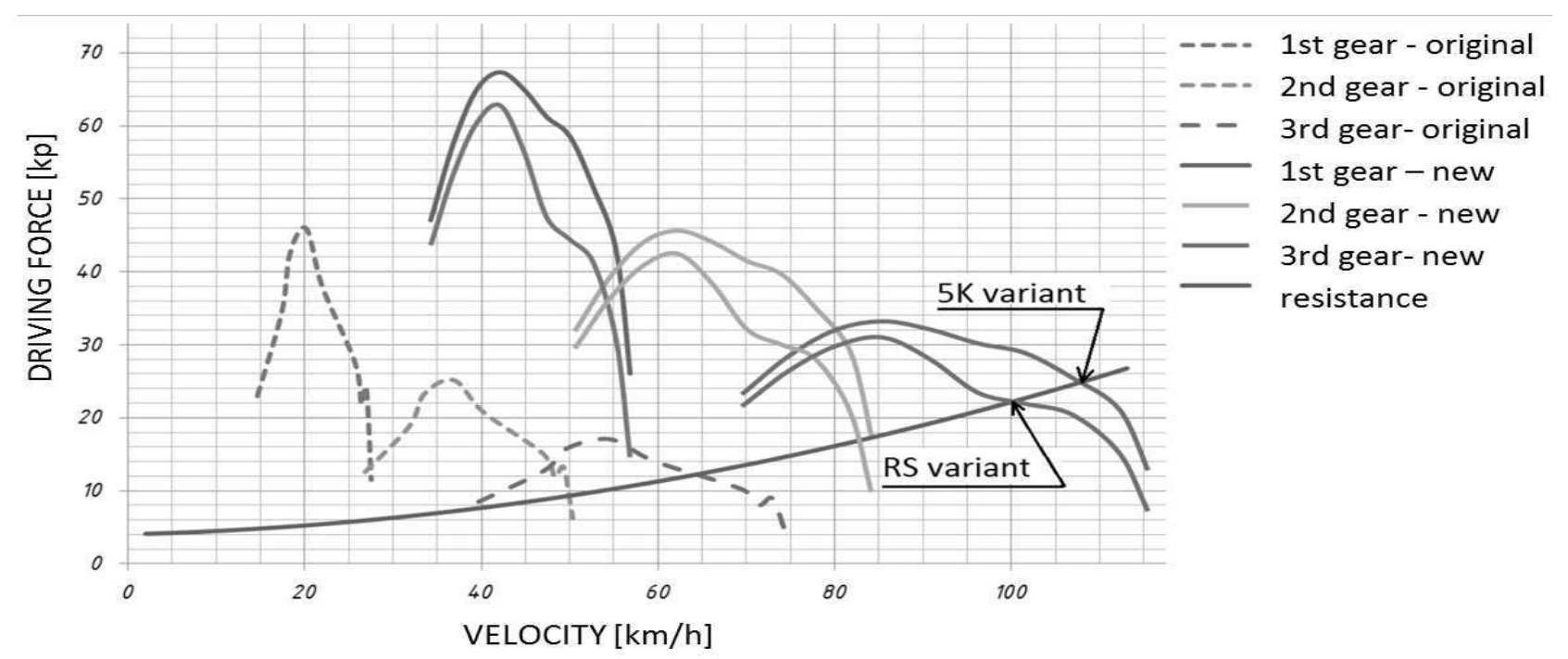

Fig. 8 Driving forces

\section{Conclusion}

The aim of this work was to design and to manufacture a cylinder liner of a $50 \mathrm{cc}$ motorcycle to increase the power characteristics so that it is possible to win the Czech road championship in the Jawa 50 RS category and the Šumava offroad racing cup. Two variants were designed. The RS variant was created only by removing material from the original cylinder. The $5 \mathrm{~K}$ variant was created from a cast iron tube and from an original aluminium case with welded ports. Both variants were manufactured using lengthened and narrowed tool holders. The biggest problem was the need to use tools with long overhangs that vibrate intensively. Because of this, the cutting velocity and cutting feed were decreased. Checking the accuracy of the manufactured dimensions confirmed that none of the required dimensions differ from the design by more than $0.05 \mathrm{~mm}$. This is a better result than expected considering the long overhang from the collet holder. Despite more complicated setting in the correct position when clamping in order to achieve good connection to the original ports, it was more difficult to produce variant $5 \mathrm{~K}$ because machining time with clamping took approximately 70 minutes. On the other hand, variant RS took about 45 minutes. Production of $5 \mathrm{~K}$ variant is more expensive because, besides other things, of the need to weld on the aluminium case. Because this is the development of a new racing component, it is clear that it has higher cost demands.

\section{Acknowledgement}

This paper is based upon work sponsored by project SGS-2016-005.

\section{References}

[1] JENNINGS, H. (1987). Two-stroke Tuner's Handbook, HP Trade,156 s, ISBN: 978-0912656410.

[2] OPLUŠTIL, V. (2010). Two-stroke engines of road racing GP motorcycles. Brno, Bachelor thesis. Brno University of Technology, available on: http://www.vutbr.cz/studium/zaverecneprace?zp_id=30424.

[3] BELL, A. (1999). Two-stroke performance tuning. 2nd ed. Newbury Park, Calif., USA: Haynes North America, 271 p. ISBN: 18-596-0619-9.

[4] BLAIR, G.P. (1996). Desing and simulation of two-stroke engines, Society of Automotive Engineers, 623 s. ISBN 1-56091-685-0.

[5] STEJSKAL, M. (2012). Increasing single cylinder si two-stroke engine performance, Diploma thesis, Brno University of Technology

[6] BLAIR,G.P. (1990). The Basic Design of Two Stroke Engines, Society of Automotive Engineers, 650 s. ISBN: 978-1560910084.

[7] BÖNSCH, H. (2014). Der schnellaufende Zweitaktmotor: Eine Einführung in die technischen Grundlagen,Motorbuch Verlag, Stuttgart,212 s. ISBN 978-3613036734.

[8] STUMR, V. (2010) The optimization of performance parameters of two-stroke engine, Bachelor thesis, University Pardubice, available on: http://dspace.upce.cz/bitstream/10195/39357/1/StumrV_Optimalizace Vykonovych_SG_2010.pdf

[9] LAIMBÖCK, F. (1998) Zweiradtechnik und Kleinmotoren. 4. erweiterte Auflage. Institut für Verbrennungskraftmaschinen und Thermodynamik, Technische Universität Graz.

[10] DAŇA, M., ZETKOVÁ, I., SCHORNÍK, V. (2015). Production Technology and a Design of Transfer Ports in a Cylinder of a Small-Volumer Motorcycle, In Procedia Engineering, ISSN 1211-4162, ISBN: 978-3-901509-99-5

[11] MADLOVA, D. GEBHART, V. (2017). Hazards in Milling, Manufacturing Technology, Vol. 17, No. 6, ISSN 1213-2489. 